\title{
Fourier Transform Measurement of NO2 Absorption Cross- sections in the Visible Range at Room Temperature.
}

\author{
A.C. Vandaele,, C. Hermans, P.C. Simon, M. Van Roozendael \\ J.M. Guilmot, M. Carleer, and R. Colin
}

\section{Abstract}

New laboratory measurement of $\mathrm{NO}_{2}$ absorption cross-sections were performed using a Fourier transform spectrometer at 2 and $16 \mathrm{~cm}^{-1}(0.03$ and $0.26 \mathrm{~nm}$ at 400 $\mathrm{nm})$ in the visible range $(380-830 \mathrm{~nm})$ and at room temperature. The use of a Fourier transform spectrometer leads to a very accurate wavenumber scale $(0.005$ $\mathrm{cm}^{-1}, 8 \times 10-5 \mathrm{~nm}$ at $400 \mathrm{~nm}$ ). The uncertainty on the new measurements is better than $4 \%$. Absolute and differential cross-sections are compared with published data, giving an agreement ranging from $2 \%$ to $5 \%$ for the absolute values. The discrepancies in the differential cross-section can however reach $18 \%$. The influence of the cross-sections on the ground-based measurement of the stratospheric $\mathrm{NO}_{2}$ total amount is also investigated.

\section{Key words}

Fourier Transform Spectroscopy, $\mathrm{NO}_{2}$, absorption cross-sections, differential absorption cross-sections, visible, stratospheric and tropospheric measurements

\section{Introduction}

Nitrogen dioxide plays an important role in the chemistry of the troposphere and the stratosphere. It is produced from the oxidation of NO in the troposphere, where it acts as the main source of tropospheric ozone, and is a precursor to species, such as nitric acid, which play a role in the acidification of the environment. Its role in stratospheric photochemistry has been pointed out by Crutzen (1970). Beside its catalytic interaction in the control of ozone, it regulates the amounts of $\mathrm{ClO}$, which in turn controls the ozone loss due to the chlorine catalytic cycle, and of $\mathrm{ClONO}_{2}$, which is an important stratospheric reservoir of chlorine. It plays thus an important role in the coupling of the $\mathrm{NO}_{x}$ and $\mathrm{ClO}_{x}$ families.

Molecular absorption in the UV-Visible region has been widely used to measure the concentrations of gases in the atmosphere, either in the troposphere or in the stratosphere. The instruments used range from ground-based spectrometers measuring tropospheric or stratospheric concentration by the Differential Optical Absorption Spectroscopy (DOAS) technique ( see for example Platt and Perner, 1980, Solomon et al., 1987, Edner et al., 1993, Vandaele et al.,1992, Evangelisti et al., 1995, Camy-Peyret et al., 1996), to spectrometers on board satellites such as the GOME ( Global Ozone Monitoring Experiment) launched in April 1995 on board ERS-2 satellite, and to SCIAMACHY and GOMOS instruments to be launched in 1999 on board ENVISAT-1. 
All these instruments require absorption cross-sections of the observed molecules, measured at a resolution of $0.02 \mathrm{~nm}$ or better and with an accuracy better than 5\% (Chance et al, 1990). Accurate cross-sections are also needed for the chemical-dynamical-radioactive modeling of the atmosphere.

The measurement of the $\mathrm{NO}_{2}$ absorption cross-section is complicated by the presence of its dimer $\mathrm{N}_{2} \mathrm{O}_{4}$. Several studies have attempted to measure $\mathrm{NO}_{2}$ cross-sections. Hall and Blacet(1952) measured absorption spectra of $\mathrm{NO}_{2}{ }^{-}$ $\mathrm{N}_{2} \mathrm{O}_{4}$ mixtures at $298 \mathrm{~K}$ and deduced the contribution of $\mathrm{N}_{2} \mathrm{O}_{4}$. Johnston and Graham (1974) measured $\mathrm{NO}_{2}$ cross-sections in the $185-420 \mathrm{~nm}$ spectral region at room temperature. Bass et al.(1976) investigated the 185-410 nm range at $298 \mathrm{~K}$. They corrected their data for the presence of $\mathrm{N}_{2} \mathrm{O}_{4}$. Leroy et al.(1987) reported values from 427 to 450 at 298K. Schneider et al.(1987) obtained NO2 absorption cross-sections between $200 \mathrm{~nm}$ and $700 \mathrm{~nm}$, at $298 \mathrm{~K}$ and determined the absorption cross-sections of N2O4 between 200 and $255 \mathrm{~nm}$. Koffend et al.(1987) used a pulsed dye laser to perform high resolution measurement of $\mathrm{NO}_{2}$ absorption structures in the $392-395 \mathrm{~nm}$ and 411-414 nm. Davidson et al.(1988) investigated the dependence of the $\mathrm{NO}_{2}$ cross-sections on temperature and the influence of this dependence on the determination of the photolysis rate of $\mathrm{NO}_{2}$ in the atmosphere. Harwood and Jones (1994) studied the temperature dependence of the ultraviolet-visible absorption cross section of $\mathrm{NO}_{2}$. The cross sections of $\mathrm{N}_{2} \mathrm{O}_{4}$. were also derived by the latter, as well as new values for the equilibrium constant. Mérienne et al.(1995) measured $\mathrm{NO}_{2}$ absorption cross-sections in the 300$500 \mathrm{~nm}$ region at $293 \mathrm{~K}$. The use of an absorption path length of $61 \mathrm{~m}$ allowed them to work at very low pressure ( $<0.04$ Torr) and to minimize the influence of the dimer. Discrepancies of the order of $20 \%$ or sometimes more are found between all the measurements.

This work presents new absolute absorption cross-sections of $\mathrm{NO}_{2}$ between 12000 and $26000 \mathrm{~cm}^{-1}(380-830 \mathrm{~nm})$ at $294 \mathrm{~K}$. The absorption cross-sections have been measured at two resolutions : 2 and $16 \mathrm{~cm}^{-1}$ ( 0.03 and $0.26 \mathrm{~nm}$ at $400 \mathrm{~nm}$ ). Cross-sections obtained in this work have been measured with a Fourier Transform Spectrometer (FTS), which combines the advantages of a great sensitivity and a built-in wavenumber calibration. This last advantage is achieved by the presence of a He-Ne laser, which allows the interferogram to be digitised at equal intervals. This leads to a highly accurate and reproducible wavenumber calibration. With the Fourier Transform Spectrometer described below, an accuracy of about $0.005 \mathrm{~cm}^{-1}(8 \times 10-5 \mathrm{~nm}$ at $400 \mathrm{~nm}$ ) on the wavenumbers is achieved. 
These new cross-sections will then be compared with published data sets, measured at similar resolutions. A comparison of cross-sections smoothed to a resolution of $1.0 \mathrm{~nm}$ will also be shown. Finally, the importance to dispose of cross-sections of high quality will be stressed, by investigating their influence on ground-based stratospheric $\mathrm{NO}_{2}$ measurements in the visible range.

\section{Experimental details}

The experimental set-up consists of a light source, the spectrometer, and the gas handling system. The choice of the light source, beam splitter and detector is determined by the spectral region to be investigated. Combinations of a high pressure $\mathrm{O}_{3}$ free Xenon source (USHIO, $450 \mathrm{~W}$ ), a Tungsten filament lamp, a Quartz Suprasil beam splitter with a Si diode or a UV vacuum solar blind diode have been used in order to cover the entire spectral region from 12000 to $26000 \mathrm{~cm}^{-1}$. A blue filter provided by BRUKER or a copper sulphate solution filter have been used. The experimental conditions are reported in Table 1. A photo feedback system allowed the lamp intensity to be stabilised within $1 \%$ throughout the experiments.

The absorption spectra were recorded using either a BRUKER IFS120HR or a BRUKER 120M Fourier Transform Spectrometer. The theoretical resolving power attainable with these spectrometers is 106. However, the resolution is essentially limited in the UV by the quality of the mirrors and beam splitter, leading to a maximum resolution of the order of $10-2 \mathrm{~cm}^{-1}$ in this region. Following some recommendations concerning the measurements of absorption cross-sections (Chance, 1990), spectra have been recorded with resolutions of 2 and $16 \mathrm{~cm}^{-1}$, corresponding respectively to 0.03 and $0.26 \mathrm{~nm}$ at $400 \mathrm{~nm}$.

NO2 gas (UCAR, stated purity of 99.5\%) used without further purification, was introduced in a $5.15 \mathrm{~cm}$ absorption cell located in the sample compartment of the Fourier Spectrometer. The partial pressure of the gas was then monitored with a 100 Torr full scale Baratron gauge. We waited until the stabilisation of the partial pressure (10 to $30 \mathrm{~min}$, without any lamp illumination ) before filling with oxygen in order to obtain a total pressure of 1 atm. The presence of oxygen is of great importance as it induces the reconversion of any $\mathrm{NO}$ into $\mathrm{NO}_{2}$, maintaining the $\mathrm{NO}_{2}$ concentration constant. NO can be present in the cell as an initial impurity or produced by the photo dissociation of $\mathrm{NO}_{2}$ during the experiment. The cell has been described in an earlier publication (Hurtmans et al., 1993). Its characteristics will be briefly summarised here : the cell is made of anodised aluminum and has quartz windows; the temperature of the gas is monitored inside the cell with a temperature transducer characterised by an accuracy of $0.2 \mathrm{~K}$ in the temperature range used in the present work. 
The temperature in the cell was stabilised with a liquid circulating around the cell. Finally, the whole experimental set-up was located in a temperature stabilised room.

Absorption of $\mathrm{NO}_{2}$ on the inner surface of the cell is inevitable. To limit this effect on the pressure measurement, we waited before and after filling the cell with oxygen. This is however not enough to guarantee a stable $\mathrm{NO}_{2}$ partial pressure throughout the experiment. Each spectrum was therefore the average of a number of scans (see Table I) which have been recorded by sequential blocks of either 256 or 1024 scans. Only the blocks of scans whose absorption did not differ from the first block by more than $1 \%$ were retained. We thus checked that the gradual decrease of the $\mathrm{NO}_{2}$ pressure inside the cell was small. Moreover it proved that photochemical degradation of the sample due to the irradiation by the lamp was not important during the experiment.

Spectra have been obtained using a double sided recording mode, during the forward movement only of the mobile mirror and no apodization function was used. Blank spectra, i.e. with an empty cell, were recorded before and after each measurement.

\section{Determination of the absorption cross-sections}

Absorption cross-sections $\mathrm{s}(\mathrm{I})$ are derived from the experimental data using the Beer-Lambert law:

$$
I(I)=I o(I) \exp (-n I s(I))
$$

where $\mathrm{n}$ is the gas concentration in the cell, I the absorption path length, $I O(I)$ and $I(I)$ the intensities of the signal with an empty cell and a filled cell.

The $\mathrm{NO}_{2} \mathrm{U} \mathrm{N}_{2} \mathrm{O}_{4}$ equilibrium implies that $\mathrm{N}_{2} \mathrm{O}_{4}$ is always present in the cell. Absorption of $\mathrm{N}_{2} \mathrm{O}_{4}$ occurs at wavenumbers greater than $25000 \mathrm{~cm}^{-1}$ (Hall and Blacet, 1952, Schneider et al.,1987), but not in the spectral region investigated in this work. $\mathrm{N}_{2} \mathrm{O}_{4}$ should not therefore interfere with the absorption structures of $\mathrm{NO}_{2}$ studied here. 
However the presence of $\mathrm{N}_{2} \mathrm{O}_{4}$ must be considered when determining the partial pressure of $\mathrm{NO}_{2}$. This was done by considering the following equations :

$$
\mathrm{P}_{\mathrm{t}}=\mathrm{P}_{\mathrm{N}_{2} \mathrm{O}}+\mathrm{P}_{\mathrm{NO}_{2}}
$$

where $P_{t}$ is the total partial pressure in the cell and the partial pressures $\mathrm{P}_{\mathrm{N}_{2}} \mathrm{O}$. and $\mathrm{P}_{\mathrm{NO}_{2}}$ are related through the equilibrium constant $\mathrm{K}_{\mathrm{P}}$ :

$$
\mathrm{K}_{\mathrm{P}}=\frac{\mathrm{P}_{\mathrm{NO}_{2}}^{2}}{\mathrm{P}_{\mathrm{N}_{2} \mathrm{O}_{4}}}
$$

where $K_{p}$ is the equilibrium constant.

Partial pressures of $\mathrm{NO}_{2}$ and $\mathrm{N}_{2} \mathrm{O}_{4}$ can thus be calculated. Hurtmans et al. (1993) reviewed the values of the equilibrium constant found in the literature and determined an empirical relation for its temperature dependence. For temperatures ranging from $233 \mathrm{~K}$ to $403 \mathrm{~K}$, the dependence was expressed by a fourth degree polynomial expansion. At 294.15K, the value of the constant $\mathrm{KP}$ is $105.72 \mathrm{hPa}$. Using the above equations the partial pressure of $\mathrm{NO} 2$ can be calculated from the various total pressures used.

The $\mathrm{NO}_{2}$ absorption cross-sections at the resolution of $16 \mathrm{~cm}^{-1}$ were obtained by taking the mean value of all the spectra i.e. all the spectra taken at $16 \mathrm{~cm}^{-1}$ and the spectrum at $2 \mathrm{~cm}^{-1}$ degraded to $16 \mathrm{~cm}^{-1}$. All measurements were found to agree within $2 \%$ which is lower than the uncertainty stated in Table II. The results are plotted in Figure 1 for the entire spectral region.

Figure 2 shows a detailed region from 22200 to $23200 \mathrm{~cm}^{-1}$ of the spectrum at the resolution of $2 \mathrm{~cm}^{-1}$.

\section{Discussion}

\section{Error evaluation}

The error budget on the absorption cross-sections was carefully evaluated, taking into account the errors on the pressure and temperature measurements, on the reaction constant $\mathrm{K}_{\mathrm{p}}$, the uncertainty on the absorption path length, the presence of possible impurities in the samples, the adsorption of $\mathrm{NO}_{2}$ taking place inside the cell and the absorbance accuracy. 
According to the error propagation principle, the uncertainty on the crosssections can be derived from the following relation :

$$
\frac{\delta \sigma}{\sigma}=\sqrt{\left(\frac{\delta \mathrm{A}}{\mathrm{A}}\right)^{2}+\left(\frac{\delta \mathrm{T}}{\mathrm{T}}\right)^{2}+\left(\frac{\delta 1}{1}\right)^{2}+\left(\frac{\delta \mathrm{P}_{\mathrm{NO}_{2}}}{\mathrm{P}_{\mathrm{NO}_{2}}}\right)^{2}}
$$

where $A$ is the absorbance $\left(A=\ln \frac{I_{0}}{I}\right)$. From the definition of the partial pressure of $\mathrm{NO}_{2}, \delta \mathrm{P}_{\mathrm{NO}_{2}}$ can be written as :

$$
\delta \mathrm{P}_{\mathrm{NO}_{2}}=\left(\frac{\partial \mathrm{P}_{\mathrm{NO}_{2}}}{\partial \mathrm{K}_{\mathrm{P}}}\right)_{\mathrm{P}_{\mathrm{t}}} \delta \mathrm{K}_{\mathrm{P}}+\left(\frac{\partial \mathrm{P}_{\mathrm{HO}_{2}}}{\partial \mathrm{P}_{\mathrm{t}}}\right)_{\mathrm{K}_{\mathrm{p}}} \delta \mathrm{P}_{\mathrm{t}}
$$

Setting, $a=\left(1+4 \mathrm{P}_{t} / \mathrm{K}_{\mathrm{P}}\right)^{1 / 2}$ one obtains

$$
\frac{\delta \mathrm{P}_{\mathrm{NO}_{2}}}{\mathrm{P}_{\mathrm{NO}_{2}}}=\left(\frac{\mathrm{a}-1}{2 \mathrm{a}}\right) \frac{\delta \mathrm{K}_{\mathrm{P}}}{\mathrm{K}_{\mathrm{P}}}+\left(\frac{4 \mathrm{P}_{\mathrm{t}}}{2 \mathrm{a}(\mathrm{a}-1) \mathrm{K}_{\mathrm{P}}}\right) \frac{\delta \mathrm{P}_{\mathrm{t}}}{\mathrm{P}_{\mathrm{t}}}
$$

Concerning $\mathrm{dK}_{\mathrm{p}}$, Roscoe and Hind (1993) reviewed different measurements of $\mathrm{K}_{\mathrm{P}}$ and came to the conclusion that the error on this constant was of the order of $5 \%$ for temperatures ranging from 233 to $300 \mathrm{~K}$. The error on the total pressure arises from the presence of impurities inside the $\mathrm{NO}_{2}$ bottle, from the adsorption of $\mathrm{NO}_{2}$ and from the measurement itself $(0.1 \%$ with the Baratron gauge). The manufacturer states a $99.5 \%$ purity $\mathrm{NO}_{2}$. An infrared study of the sample

( Hurtmans et al. ,1993; Vander Auwera, personal communication ) showed that small amounts of $\mathrm{N}_{2} \mathrm{O}$ and $\mathrm{CO}_{2}$ were present in the sample, as well as negligible amounts of $\mathrm{HNO}_{2}$ and $\mathrm{HNO}_{3}$. These species do not interfere with the $\mathrm{NO}_{2}$ absorption in the visible region but cause an error on the determination of its partial pressure. NO is also present as an impurity in the sample, but the presence of oxygen ensures its conversion into $\mathrm{NO}_{2}$. An estimated value of $2 \%$ is believed to cover the uncertainties due to all impurities. As already explained, the adsorption of $\mathrm{NO}_{2}$ on the inner walls of the cell causes a decrease of absorption estimated at $1 \%$ throughout an experiment. The error on the absorbance for each individual spectrum was less than $1 \%$.

The cumulative error is given in Table II. According to these figures, the accuracy on the present cross-section measurement of $\mathrm{NO}_{2}$ can be stated to be better than $4 \%$. 


\section{Comparison with published measurements}

$\mathrm{NO}_{2}$ absorption cross-sections will be compared below with the data from Schneider et al.(1987), Johnston and Graham (1974), Harwood and Jones(1994), and Mérienne et al. (1995), taking into account the conversion of wavelengths to wavenumbers and the correction of wavelengths from air to vacuum when necessary.

\section{Comparison of data at high resolution}

Data from Schneider et al.( $298 \mathrm{~K}$, resolution of $0.04 \mathrm{~nm}$ ), Johnston and Graham ( $294 \mathrm{~K}$, resolution of $0.1 \mathrm{~nm}$ ), and Mérienne et al. ( $293 \mathrm{~K}$, resolution of $0.01 \mathrm{~nm}$ ) have been convolved in order to obtain a resolution equivalent to $16 \mathrm{~cm}^{-1}$ and have been compared to our measurement at this resolution. The cross-sections were smoothed using a Gaussian function, whose width was given by the desired resolution. Results are plotted in Figures 3 and 4. Figure 3 shows the absolute absorption cross-sections of $\mathrm{NO}_{2}$ from the four groups of authors in the spectral region from 415 and 465 $\mathrm{nm}$. Figure 4 presents the relative difference (expressed in \%) between our data and those of Johnston and Graham and of Mérienne et al. The results appear to be « noisy ». It must be remembered however that the necessary conversion of the wavelengths to wavenumbers may introduce artefacts, which could explain some of the noise found in the residuals. Moreover, it is almost impossible to convolve a spectrum so that its new resolution perfectly matches the resolution of another spectrum. This produces yet additional noise in the residual. But the most important source of noise comes from errors in the calibration of the wavelength scale. The wavenumber scale produced by the FTS is linear and absolute, and that wavelength scales produced by grating spectrometers are not and may be shifted or distorted. Moreover, as grating spectrometers usually work on smaller spectral regions, large errors may be introduced when joining two scanned regions. All these errors on the wavelength scale account for most of the noise found in the residuals.

The difference between our data and those of Schneider et al. is considerable (10\% to $25 \%)$ and greatly varies with wavelength. Data from Schneider et al. are systematically lower in the 380-426 nm region, as expected if photo dissociation of $\mathrm{NO}_{2}$ was taking place in their experiment. Moreover, a large discrepancy in the wavelength scale is observed in some parts of the spectrum. It seems that errors were introduced in the data set of Schneider et al. when merging two contiguous spectral regions. 
The comparison with the results of Johnston and Graham shows that values found in our work are systematically $5 \%$ lower between 415 and $500 \mathrm{~nm}$. For wavelengths higher than $525 \mathrm{~nm}$, data from Johnston and Graham are lower by $5 \%$. Attention should be paid to the fact that a wavelength shift of the complete data set of Johnston and Graham of $0.25 \mathrm{~nm}$ has been applied in order to make the absorption structures coincide.

The comparison of our data with the data of Mérienne et al. shows a very good agreement ( less than $2 \%$ ). This result is noteworthy as it must be pointed out that the two sets of data were obtained with completely different spectrometers and instrumental set-ups. Moreover a comparison of the two sets at the higher resolution ( $2 \mathrm{~cm}^{-1}$ ) has been made, showing (Figure 5) again a difference of only $2 \%$ between the two sets of data.

\section{Comparison of data at low resolution}

In order to compare the $\mathrm{NO}_{2}$ absorption cross-sections obtained in this work with the data from Harwood and Jones (1994) ( $298 \mathrm{~K}$, resolution of 0.54 $\mathrm{nm}$ ), all data sets have been convolved to a chosen resolution of $1.0 \mathrm{~nm}$ using a Gaussian function ( see 4.2.1). The resolution of most of DOAS grating instruments lies usually in the range between 0.5 and $1.2 \mathrm{~nm}$; a resolution of $1.0 \mathrm{~nm}$ is therefore representative for that kind of instruments.

Convolved absolute cross-sections of Harwood and Jones are systematically lower by $5 \%$ than the convolved data measured in this work. The differences reach however $15 \%$ in the 430 to $440 \mathrm{~nm}$ region.

As the DOAS technique is based on the differential cross-sections of the absorbing molecules rather than their absolute cross-sections, differential cross-sections derived from the measurements of the various groups were also compared. Differential cross-sections are obtained by smoothing the absolute cross-sections to remove all the absorption structures from the spectrum, and by subtracting this smoothed curve from the absolute crosssection. The data have been smoothed with a running average over a number of points corresponding to a spectral interval of $25 \mathrm{~nm}$.

The comparison has been limited to the $410-460 \mathrm{~nm}$ region, where the DOAS stratospheric $\mathrm{NO}_{2}$ measurements are usually performed ( Hofmann et al., 1995). Results are reported in Figure 6, where differential cross-sections and their differences relative to our data are presented. Shifts in the wavelength scales in the data of Schneider et al. and of Johnston and Graham have not been corrected. The good agreement between the data of this work and those of Mérienne et al. is again confirmed. 
Once the shift in the data of Johnston and Graham is taken into account, their differential absorption structures appear to agree very well (less than $2 \%$ ). A shift in the data of Schneider et al. clearly visible above $425 \mathrm{~nm}$ could not be corrected as it is not constant over the entire range; differences up to $70 \%$ are therefore present.

Table III shows more clearly the differences existing between the various data sets. Each differential cross-section has been compared to the differential cross-sections of this work. Shifts in the wavelength scale and correction factor of the amplitude were thus determined. The fitted region ranged from 410 to $460 \mathrm{~nm}$ when possible. For values of Schneider et al., two regions were chosen, as their shift is highly dependent on the wavelength region. In the $410-420 \mathrm{~nm}$ region they do not present any significant shift compared to the data of Mérienne et al. In the 450-460 nm region, a shift of $0.58 \mathrm{~nm}$ relative to our data is present. However, once this shift has been taken into account, differential cross-sections agree well. Altogether differential cross-sections agree within $1.5 \%$ in amplitude except for the data of Harwood and Jones.

\section{Influence of the cross-sections on stratospheric NO2 measurements}

The measurements of the $\mathrm{NO}_{2}$ concentration in the atmosphere, either the stratosphere or the troposphere, mostly rely today on the use of the spectroscopic signature of the molecule. The $\mathrm{NO}_{2}$ amount is usually determined using the intense absorption structures located between 400 and $600 \mathrm{~nm}$, but its spectrum must be taken into account on the whole UV/visible range in order to eliminate its interference with the absorption of other molecules.

The need for $\mathrm{NO}_{2}$ cross-section values of high quality has recently been illustrated in a NDSC (Network for the Detection of Stratospheric Change) campaign, focused on the measurements of stratospheric $\mathrm{NO}_{2}$ using various UV/Visible spectrometers (Hofmann et al., 1995). Seven instruments participated in the campaign. Each instrument worked with a different $\mathrm{NO}_{2}$ cross-section more suited to its instrumental function. It was decided to calibrate all the instruments by the use of $\mathrm{NO}_{2}$ cell measurements. The participants thus derived a correction factor lying between 0.96 to 1.08 to apply on their $\mathrm{NO}_{2}$ data. This means that based on the choice of the $\mathrm{NO}_{2}$ absorption cross-sections, a discrepancy of $12 \%$ on the $\mathrm{NO}_{2}$ concentration was avoided.

The Institute for Space Aeronomy participated in this campaign with a ground based instrument developed for stratospheric studies. This instrument has already been described in a previous paper (Van Roozendael et al., 1994) and will only be briefly summarised here. 
The instrument records spectra of the zenith scattered sunlight and is optimised for the detection of $\mathrm{NO}_{2}$ and $\mathrm{O}_{3}$ in the visible. The detector used is an EG\&G Reticon photodiode array (1024 pixels). The spectral range extends from 400 to $560 \mathrm{~nm}$, with a resolution of $1.0 \mathrm{~nm}$ corresponding to a sampling ratio of 6.6 pixels/FWHM. The software permits a shift and a stretch of the wavelength scale of the cross-section with respect to the analysed spectrum.

Zenith sky spectra recorded at Harestua (Norway) on day number 218, 1995 have been analysed with the different absorption cross-sections mentioned above, convolved with the instrumental function of the instrument. The relative differences in $\mathrm{NO}_{2}$ column abundance are plotted in Figure $7 \mathrm{a}$. Column abundances calculated with our cross-sections have been chosen as references. The scatter of points at lower $\mathrm{NO}_{2}$ slant amount is due to the increase of the noise relative to the $\mathrm{NO}_{2}$ differential signature. Results calculated with the differential cross-sections obtained in this work, those of Johnston and Graham, and those of Mérienne et al. do agree well

( within less than 1\%). Results derived from Harwood and Jones are about $18 \%$ higher. These results mainly reproduce the differences observed between the differential cross-sections themselves. More interesting are the results plotted in Figure 7b, where the standard deviations on the NO2 slant amount have been represented as a function of the $\mathrm{NO}_{2}$ slant column. This is representative of how well the absorption cross-sections compare with the absorption signatures found in the atmospheric spectra. Except at high $\mathrm{NO}_{2}$ slant amounts, corresponding to very high zenith angles and thus very low signal to noise ratio, the standard deviation should be independent of the $\mathrm{NO}_{2}$ slant amount if no instrumental factor interferes. The fact that the evolution is linear reflects the crucial effect of the shape of the differential structures of the absorption cross-sections. Cross-sections of this work, Mérienne et al. and Johnston and Graham lead to similar standard deviations, although cross-sections of Harwood and Jones lead to a higher dependence in the $\mathrm{NO}_{2}$ amount.

We have also used cross-sections measured at lower temperatures by Coquart et al.(1995) to determine the $\mathrm{NO}_{2}$ amount. It should be pointed out that the spectrum of $\mathrm{NO}_{2}$ is composed of a series of narrow structures, whose width are of the order of or lower than the resolutions used for the laboratory data. Moreover their shape varies with temperature. This effect is of great importance when monitoring the stratospheric $\mathrm{NO}_{2}$, as temperature in the stratosphere can be as low as $190 \mathrm{~K}$. Residuals of the fitting procedure applied to derive the $\mathrm{NO}_{2}$ amount were found to be correlated with the temperature dependence of the cross-sections (Hoffman et al., 1995). 
The cross-sections of Coquart et al. (1995) measured at $220 \mathrm{~K}$ and $240 \mathrm{~K}$ have also been used to measure the $\mathrm{NO}_{2}$ amount in the spectra recorded at Harestua, during day number 218. Results are plotted in Figure 7. The $\mathrm{NO}_{2}$ slant columns are $14 \%$ and $20 \%$ lower when using absorption cross-sections at $240 \mathrm{~K}$ and $220 \mathrm{~K}$ respectively, but the standard deviation on these results are lower. This lower error level is consistent with the observation of an absorption arising from $\mathrm{NO}_{2}$ situated in the stratosphere at altitudes where the temperature is of the order of $220-240 \mathrm{~K}$. The evolutions of the standard deviation with the $\mathrm{NO}_{2}$ slant column at the two low temperatures are very similar. The residual error level attained is believed to result mainly from errors due to the convolution process or the variation of the resolution in the spectral range studied. These results confirm the necessity to take into account the temperature dependence of the absorption cross-sections. This dependence affects not only the amplitude of the differential structures of the cross-sections, but also their shape.

\section{Conclusions}

$\mathrm{NO}_{2}$ absolute absorption cross-sections have been measured at room temperature at resolutions of 2 and $16 \mathrm{~cm}^{-1}(0.03 \mathrm{~nm}$ and $0.26 \mathrm{~nm}$ at $400 \mathrm{~nm}$ respectively). The accuracy on these new measurements is believed to be better than $4 \%$, with an accuracy on the wavenumber scale of $0.005 \mathrm{~cm}^{-1}$ ( $8 \times 10-5 \mathrm{~nm}$ at $400 \mathrm{~nm}$ ). Absolute and differential cross-sections have been compared to other data sets generally used in atmospheric measurements. Our data show good agreement with data of Mérienne et al.(1995) (better than 2\%). Data from Johnston and Graham (1974) present a difference of 5\% in the absolute cross-sections, however the differential cross-sections are in better agreement. The wavelength scale of their data shows a systematic shift compared to the scale of the Fourier transform spectrometer. Data from Schneider et al. (1987) show large discrepancies in the wavelength scale. Absolute cross-sections of Harwood and Jones (1994) are systematically 5\% lower, and the differential cross-sections are $18 \%$ higher.

These cross-sections and those measured at lower temperatures by Coquart et al. (1995) have been convolved at a resolution of $1.0 \mathrm{~nm}$ and used to derive $\mathrm{NO}_{2}$ slant amounts measured with a DOAS stratospheric instrument. The results of this comparison show the good quality of the new measurements but demonstrates also the need to take into account the temperature dependence of the cross-sections. New measurements of this temperature dependence will be undertaken soon.

All the data obtained during this work are available on floppy disks, either on a wavenumber or a wavelength scale. 


\section{Acknowledgements}

This project has been supported by the Belgian State - Prime Minister's Service Science Policy Office ( contracts GC/35/002, E7/35/11P, and WI/35/004 ) and the "Fonds National de la Recherche Scientifique".

\section{References}

Amoruso A., Crescentini, L., Fiocco, G., and M. Volpe, 1993, New measurements of the NO2 absorption cross-section in the 440- to 460-nm region and estimates of the NO2 -N2O4 equilibrium constant, J. Geophys. Res. 98, 16857-16863

Bass, A.M., Ledford, A.E. and Laufer, A.H., 1976 , Extinction coefficients of NO2 and N2O4, J. Res. Nat. Bur. Stand. A 80, 143-166

Camy-Peyret, C., Bergquist, B.,. Galle, B,. Carleer, M, Clerbaux, C., Colin, R., Fayt, C., Goutail, F., Nunes-Pinharanda, M., Pommereau, J.P., Hausmann, M., Platt, U., Pundt, I., Rudolph, T., Hermans, C., Simon, P.C., Vandaele, A.C., Plane, J., and Smith, N., 1996, Intercomparison of Instruments for Tropospheric Measurements using Differential Optical Absorption Spectroscopy, J. Atm. Chem. 23, $51-80$

Chance, K.V., Burrows, J.P., Meller, R., Moortgat, G.K., Perner, D., and Schneider, W., 1990, Database needs for UV/Visible atmospheric spectroscopy, in : Atmospheric Spectroscopy Applications Workshop, ed. A. Barbe, A. Ponomarev, N. Yu, and R. Zander, 186-194, Moscow

Coquart B., Jenouvrier, A., and Mérienne, M.F., 1995, The NO2 absorption spectrum. II Absorption cross-sections at low temperatures in the $400-500 \mathrm{~nm}$ region, J. Atmos. Chem. 21, 251-261

Crutzen, P., 1970, The influence of nitrogen oxide on the atmospheric ozone content, Q. J. R. Meteorol. Soc. 96, 320

Davidson, J.A., Cantrell, C.A., McDaniel, A.H., Shifter, R.E., Madronich, S., and Calvert, J.G., 1988, Visible-ultraviolet absorption cross-sections for NO2 as a function of temperature, J. Geophys. Res. 93, 7105-7112

Edner, H., Ragnarson, P., Spännare, S., and Svanberg, S., 1993, Differential optical absorption spectroscopy (DOAS) system for urban atmospheric pollution monitoring, Appl. Optics 32, 327-332

Evangelisti, F., Baroncelli, A., Bonasoni, P., Giovanelli, G., and Ravegnani, F., 1995, Differential optical absorption spectrometer for measurement of tropospheric pollutants, Appl. Optics 34, 2737-274 
Hall, Jr. T.C., and Blacet, F.E., 1952, Separation of the absorption spectra of $\mathrm{NO} 2$ and N2O4 in the range of 2400-5000A, J. Chem. Phys. 20, 1745-1749

Harwood, M.H. and Jones, R.L., 1994, Temperature dependent ultravioletvisible absorption cross-sections of NO2 and N2O4 : low-temperature measurements of the equilibrium constant for $2 \mathrm{NO} 2$ « N2O4, J. Geophys. Res. 99, 22955-22964

Hofmann, D.J., Bonasoni, P., De Mazière, M., Evangelisti, F., Francois, P., Giovanelli, G., Goldman, A., Goutail, F., Harder, J., Jakoubek, R., Johnston, P., Kerr, J., McElroy, T., McKenzie, R., Mount, G., Pommereau, J.-P., Simon, P., Solomon, S., Stutz, J., Thomas, A., Van Roozendael, M., and Wu, E., 1995, Intercomparison of UV/Visible Spectrometers for Measurements of Stratospheric NO2 for the Network for the Detection of Stratospheric Change, J. Geophys. Res. 100,16765-16791

Hurtmans, D., Herman, M., and Vander Auwera, J., 1993, Integrated band intensities in N2O4 in the infrared range, J. Quant. Spectrosc. Transfer 50, 595-602

Johnston, H.S. and Graham, R., 1974, Photochemistry of NOx and HNOx compounds, Can. J. Chem. 52, 1415-1423

Koffend, J.B., Holloway, J.S, Kwok, M.A., and Heider, R.F., 1987, High resolution absorption spectroscopy of NO2, J. Quant. Spectrosc. Transfer 37, 449-453

Leroy, B., Rigaud, P. and Hicks, E., 1987, Visible absorption cross-sections of NO2 at 298K and 235K, Annales Geoph. 5A, 247-250

Mérienne, M.F., Jenouvrier, A. and Coquart, B., 1995, The NO2 absorption spectrum. I: Absorption cross-sections at ambient temperature in the 300-500 nm region, J. Atmos. Chem. 20, 281-297

Platt, U. and Perner, D., 1980, Direct measurements of atmospheric $\mathrm{CH} 2 \mathrm{O}$, $\mathrm{HNO} 2, \mathrm{O} 3, \mathrm{NO} 2$, and $\mathrm{SO} 2$ by differential optical absorption in the near UV, J. Geophys. Res. 85, 7453-7458

Roscoe, H.K., and Hind, A.K., 1993, The equilibrium constant of NO2 with $\mathrm{N} 2 \mathrm{O} 4$ and the temperature dependence of the visible spectrum of $\mathrm{NO} 2: \mathrm{a}$ critical review and the implications for measurements of NO2 in the polar stratosphere, J. Atmos. Chem.16, 257-276 
Schneider, W., Moortgat, G.K., Tyndall, G.S. , and Burrows, J.P., 1987, Absorption cross-sections of NO2 in the UV and Visible region (200 - 700 $\mathrm{nm}$ ) at 298K, J. Photochem. and Photobiol., A : Chem. 40, 195-217

Solomon S., Schmeltekoff A.L., and Sanders R.W., On the interpretation of zenith sky absorption measurements, J. Geophys. Res. 92, 8311 (1987)

Vandaele, A.C., Carleer, M., Colin, R., and Simon, P.C., 1992, Detection of urban O3, NO2, $\mathrm{H} 2 \mathrm{CO}$ and $\mathrm{SO} 2$ using Fourier Transform Spectroscopy, in :Optical Methods in Atmospheric Chemistry,ed. H. Schiff and U. Platt, SPIE Proc. vol 1715, The International Society for Optical Engineering, Bellingham, Washington, 288-292

Vandaele, A.C., Simon, P.C., Guilmot, J.M., Carleer, M., and Colin, R., 1994, SO2 Absorption Cross-section Measurement in the UV using a Fourier Transform Spectrometer, J. Geophys. Res. 99, 25599-25605

Van Roozendael, M., Fayt, C., Bolsée, D., Simon, P.C., Gil, M., Yela, M. , and Cacho, J., 1984, Ground-based stratospheric NO2 monitoring at Keflavik (Iceland) during EASOE, Geophys. Res. Lett. 21, 1379-1382 
Table I : Experimental conditions

\begin{tabular}{|c|c|c|c|c|c|c|}
\hline Res & $\mathrm{Pt}$ & Nb of scans & Source1 & Filter2 & Detector & Spectral Region \\
\hline $\mathrm{cm}-1$ & $\mathrm{hPa}$ & & & & & $\mathrm{cm}-1$ \\
\hline 16 & 10.18 & $8 \times 256$ & W & $\mathrm{b}$ & Si-diode & $\begin{array}{l}9500-26000 \\
(380-1050 \mathrm{~nm})\end{array}$ \\
\hline 16 & 29.50 & $14 \times 256$ & W & $\mathrm{b}$ & Si-diode & $9500-26000$ \\
\hline 16 & 29.90 & $4 \times 1024$ & W & $b$ & Si-diode & $9500-26000$ \\
\hline 16 & 50.50 & $4 \times 1024$ & W & $b$ & Si-diode & $9500-26000$ \\
\hline 16 & 67.70 & $3 \times 1024$ & W & b & Si-diode & $9500-26000$ \\
\hline 16 & 10.70 & $4 \times 1024$ & W & $\mathrm{Cu}^{++}$ & Si-diode & $\begin{array}{l}15000-30000 \\
(330-670 \mathrm{~nm})\end{array}$ \\
\hline 16 & 15.18 & $4 \times 1024$ & W & $\mathrm{Cu}^{++}$ & Si-diode & $15000-30000$ \\
\hline 16 & 20.02 & $4 \times 1024$ & W & $\mathrm{Cu}^{++}$ & Si-diode & $15000-30000$ \\
\hline 16 & 30.27 & $4 \times 1024$ & W & $\mathrm{Cu}^{++}$ & Si-diode & $15000-30000$ \\
\hline 16 & 39.30 & $4 \times 1024$ & W & $\mathrm{Cu}^{++}$ & Si-diode & $15000-30000$ \\
\hline 16 & 48.65 & $4 \times 1024$ & W & $\mathrm{Cu}^{++}$ & Si-diode & $15000-30000$ \\
\hline 2 & 13.85 & $4 \times 1024$ & $x$ & $b$ & UV-diode & $15000-30000$ \\
\hline \multicolumn{7}{|c|}{ 1W=Tungsten filament lamp, $X=$ High Pressure $X e n o n$ lamp } \\
\hline
\end{tabular}

Table II : Estimate of the accuracy of cross-sections measurements

\begin{tabular}{|l|c|}
\hline & Error \\
\hline & $(\%)$ \\
\hline Sample impurities & 2 \\
\hline Adsorption inside the cell & 1 \\
\hline Absorbance on individual spectra & 1 \\
\hline Absorption path length & 0.5 \\
\hline Pressure & 0.1 \\
\hline Temperature & 0.1 \\
\hline Cumulative error & $<4$ \\
\hline
\end{tabular}


Table III : Comparison of the differential cross-sections

\begin{tabular}{|l|c|c|c|}
\hline & Fit Range $(\mathrm{nm})$ & Shift $(\mathrm{nm})$ & $\begin{array}{c}\text { Correction Fac- } \\
\text { tor }\end{array}$ \\
\hline This work & & 0 & 1 \\
\hline Mérienne et al. & $410-460$ & 0.03 & 1.003 \\
\hline Hawwood and Jones & $410-460$ & 0.04 & 1.160 \\
\hline Johnston and Graham & $415-460$ & 0.24 & 1.002 \\
\hline Schneider et al. & $410-420$ & 0.03 & 1.017 \\
\hline Schneider et al. & $450-460$ & 0.58 & 1.018 \\
\hline
\end{tabular}

\section{Figure captions}

Figure 1. Absolute absorption cross-sections of $\mathrm{NO}_{2}$ at the resolution of 1 $\mathrm{cm}^{-1}$ at room temperature.

Figure 2. Absolute absorption cross-sections of $\mathrm{NO}_{2}$ at the resolution of 2 $\mathrm{cm}^{-1}$ at room temperature from 22200 to $23200 \mathrm{~cm}^{-1}$.

Figure 3. Comparison of absolute cross-sections of this work ( $3 / 4)$, Mérienne et al.(1995) $(\times \times \times \times \times)$, Johnston and Graham (1974) $(-x-)$, and Schneider et al. (1987) ( - - ). All data from the literature have been convolved to correspond to the resolution of $16 \mathrm{~cm}^{-1}$. The wavenumber scale of Johnston and Graham has been shifted by $5 \mathrm{~cm}^{-1}$. No shift in the wave number scale of Schneider et al. has been applied as it is not constant on the entire spectral range.

Figure 4. Relative differences between the absolute cross-sections of Mérienne et al.(1995) (3/4), Johnston and Graham (1974) $(\times \times \times \times \times)$, convolved to $16 \mathrm{~cm}^{-1}$, and the cross-sections of this work. The wavenumber scale of Johnston and Graham has been shifted by $5 \mathrm{~cm}^{-1}$. The mean value and the1s deviation for the data of Mérienne et al. are also presented.

Figure 5. Relative differences between the absolute cross-sections of Mérienne et al.(1995) convolved to $2 \mathrm{~cm}^{-1}$, and the cross-sections of this work. The mean value and the 1 ds deviation are also presented. 
Figure 6. (a) Comparison of the NO2 differential cross-sections in the 410-460 nm spectral range : $(3 / 4)$ this work, $(\times \times \times \times \times)$ Mérienne et al(1995), (- - ) Johnston and Graham (1974), ( $-x-$ ) Schneider et al. (1987), and $(-x \times-)$ Harwood and Jones (1994). Shifts in the wavelength scales of Johnston and Graham and Schneider et al. have not been corrected. (b) Differences in the NO2 differential cross-sections with respect to the data of this work.

Figure 7. Influence of the absorption cross-section on the determination of stratospheric NO2 column abundances. Results shown correspond to zenith sky measurements made at Harestua (Norway) on julian day 218, 1995 using the crosssections of this work ( $\mathrm{I}$ ), Mérienne et al(1995)

( $m$ ), Johnston and Graham (1974) ( $\check{S}$ ), Harwood and Jones (1994, data at $298 \mathrm{~K}$ )

$(\tilde{N})$, and Coquart et al. (1995) at $240 \mathrm{~K}$ ( à ) and $220 \mathrm{~K}$ ( D ). The differences in NO2 column amount relative to the NO2 amounts found with the cross-sections of this work are plotted in Figure 7.a, and the standards deviations on the measurements in Figure 7.b

Figure 1.

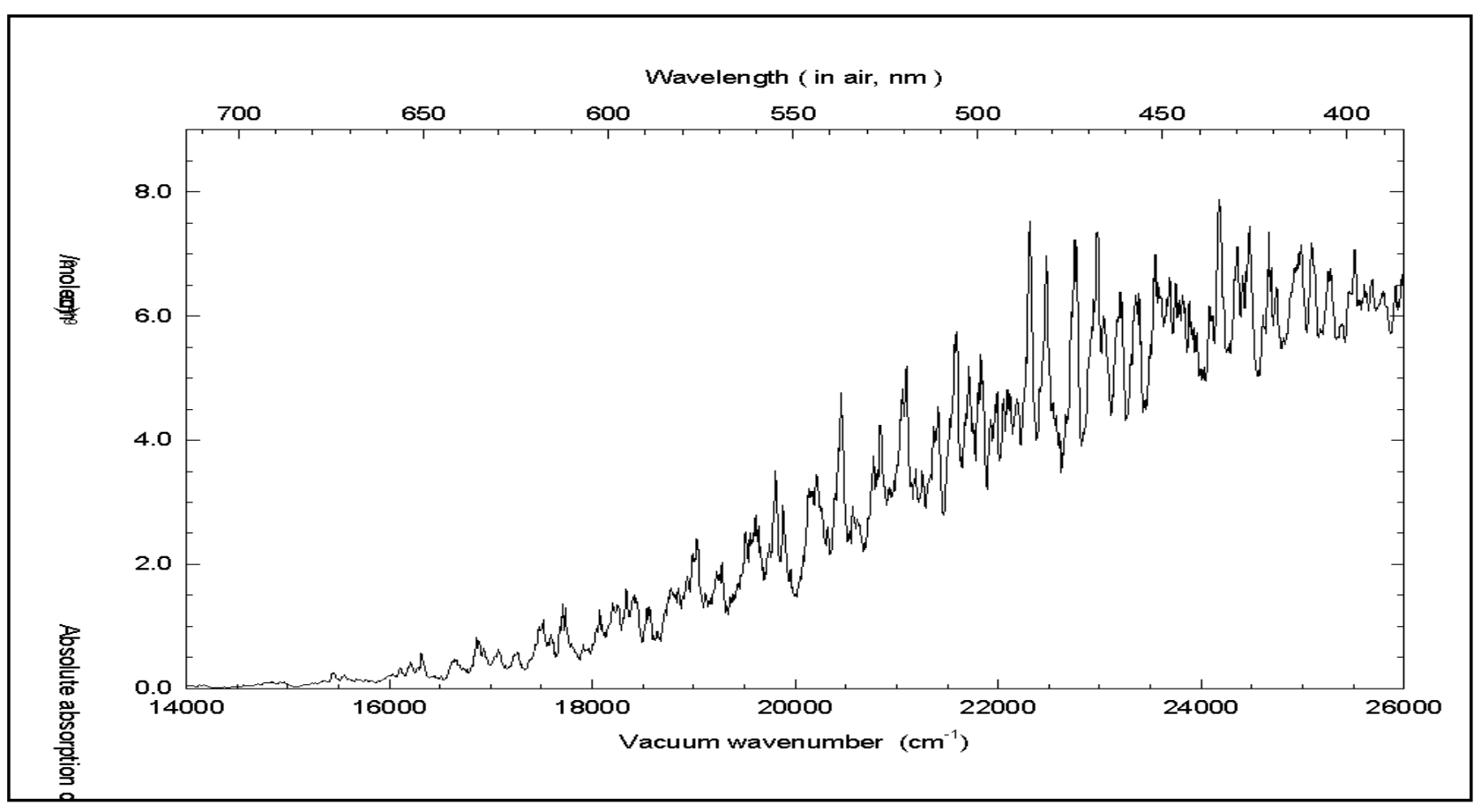


Figure 2.

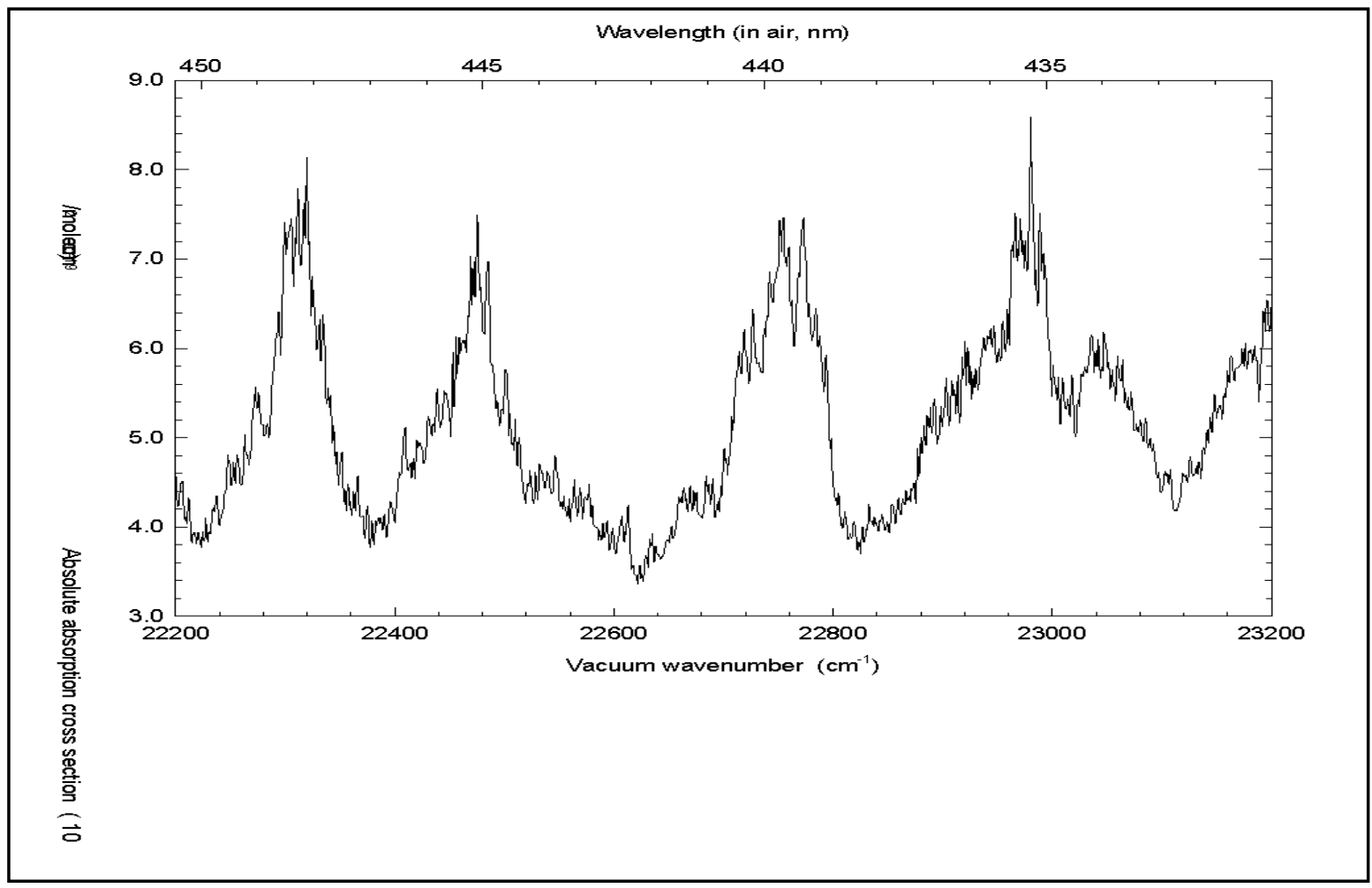

Figure 3.




Figure 4.

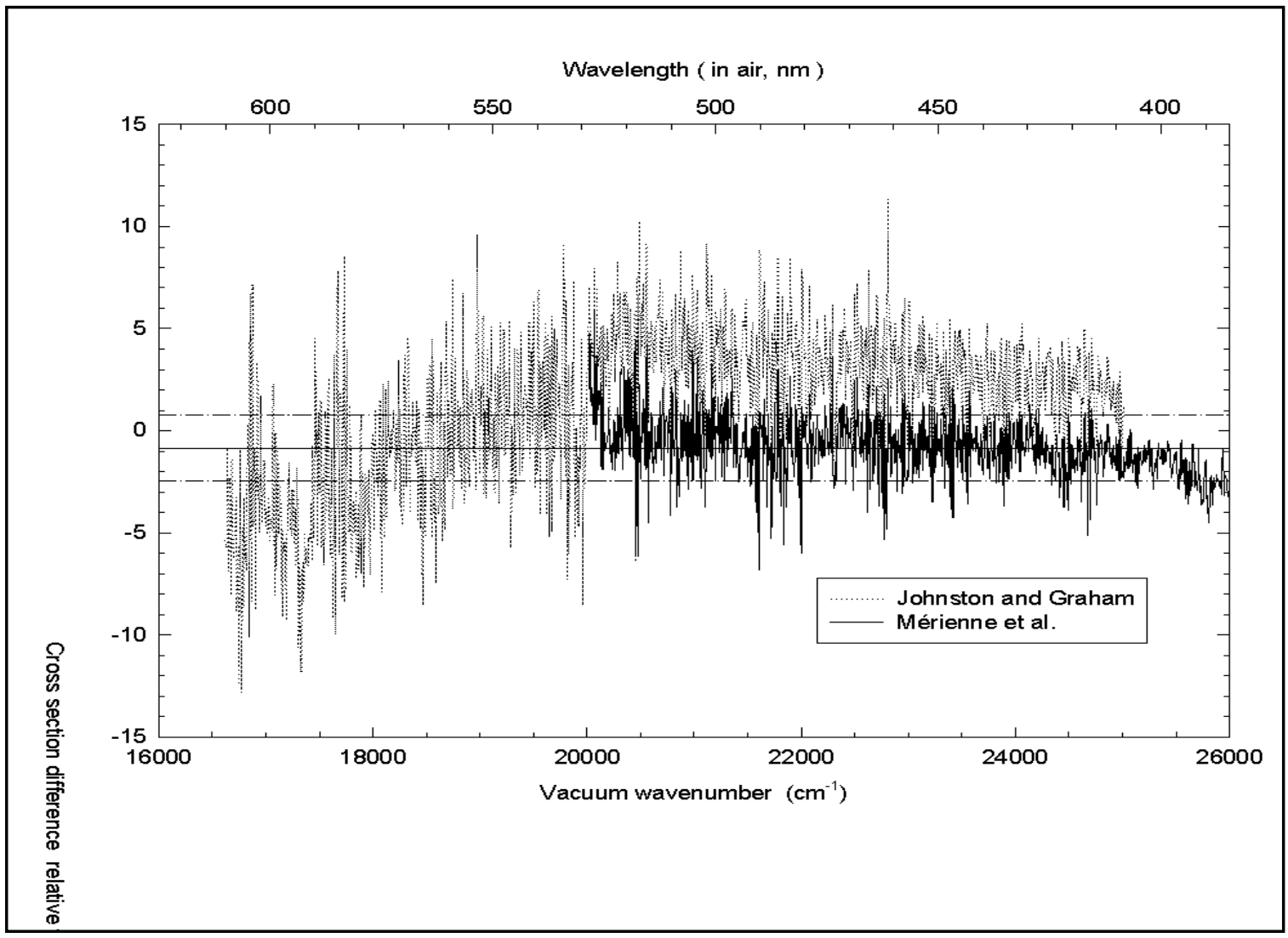

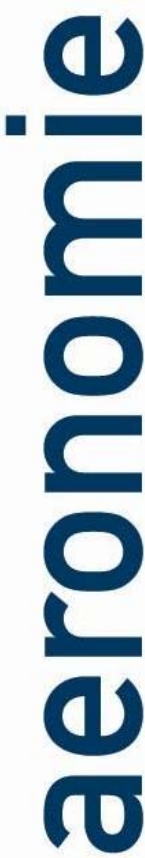

Figure 5.
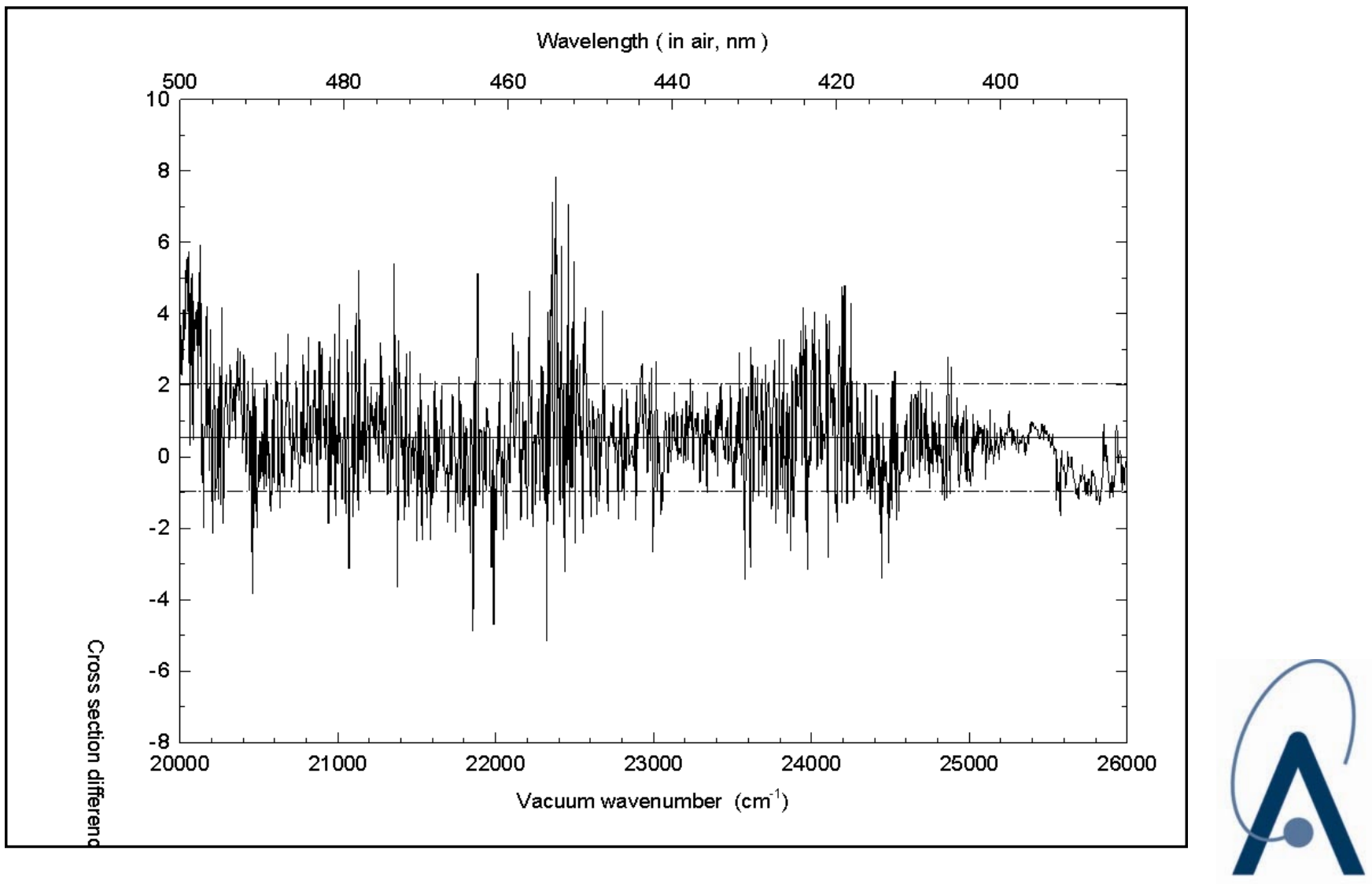
Figure 6.

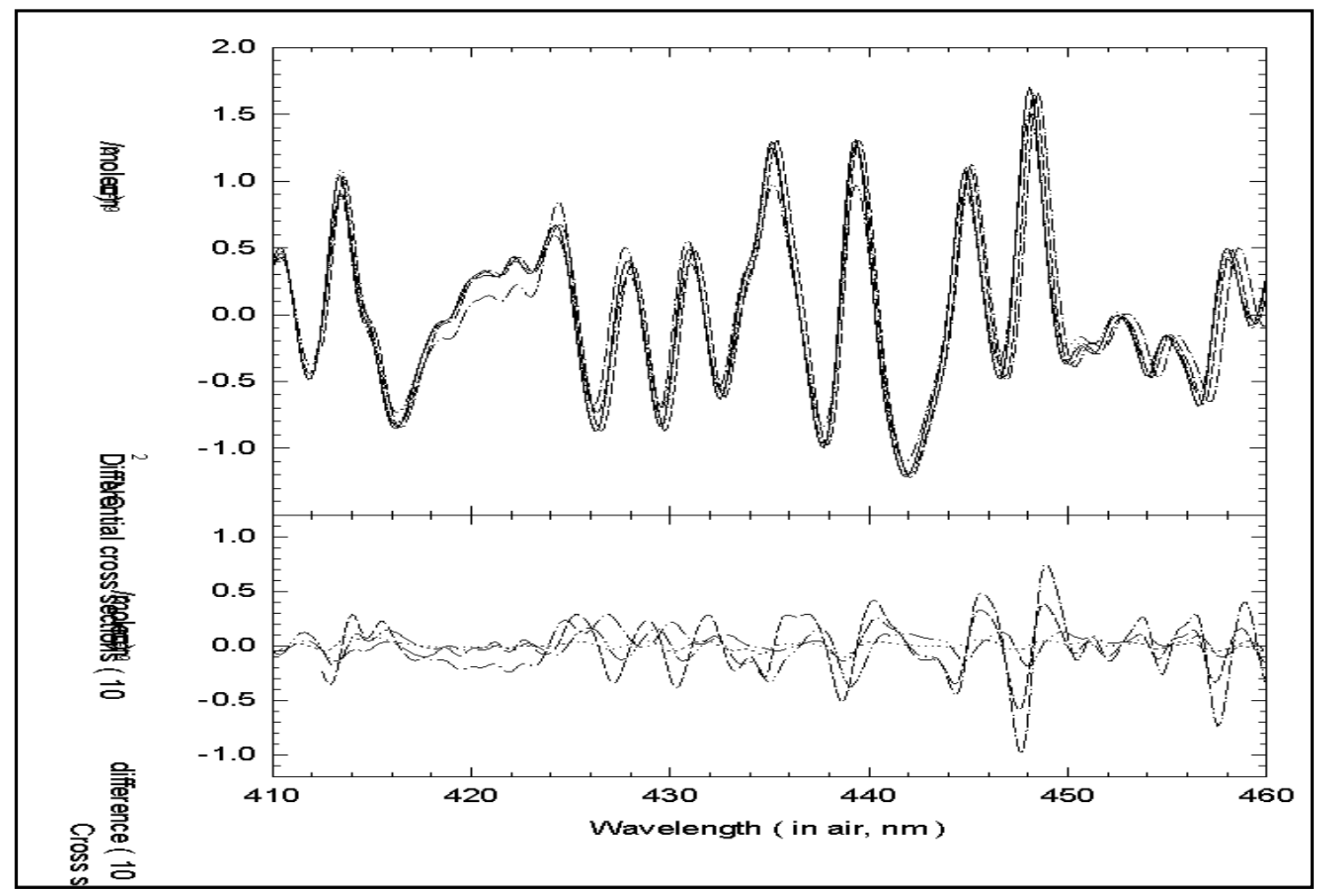

Figure 7.

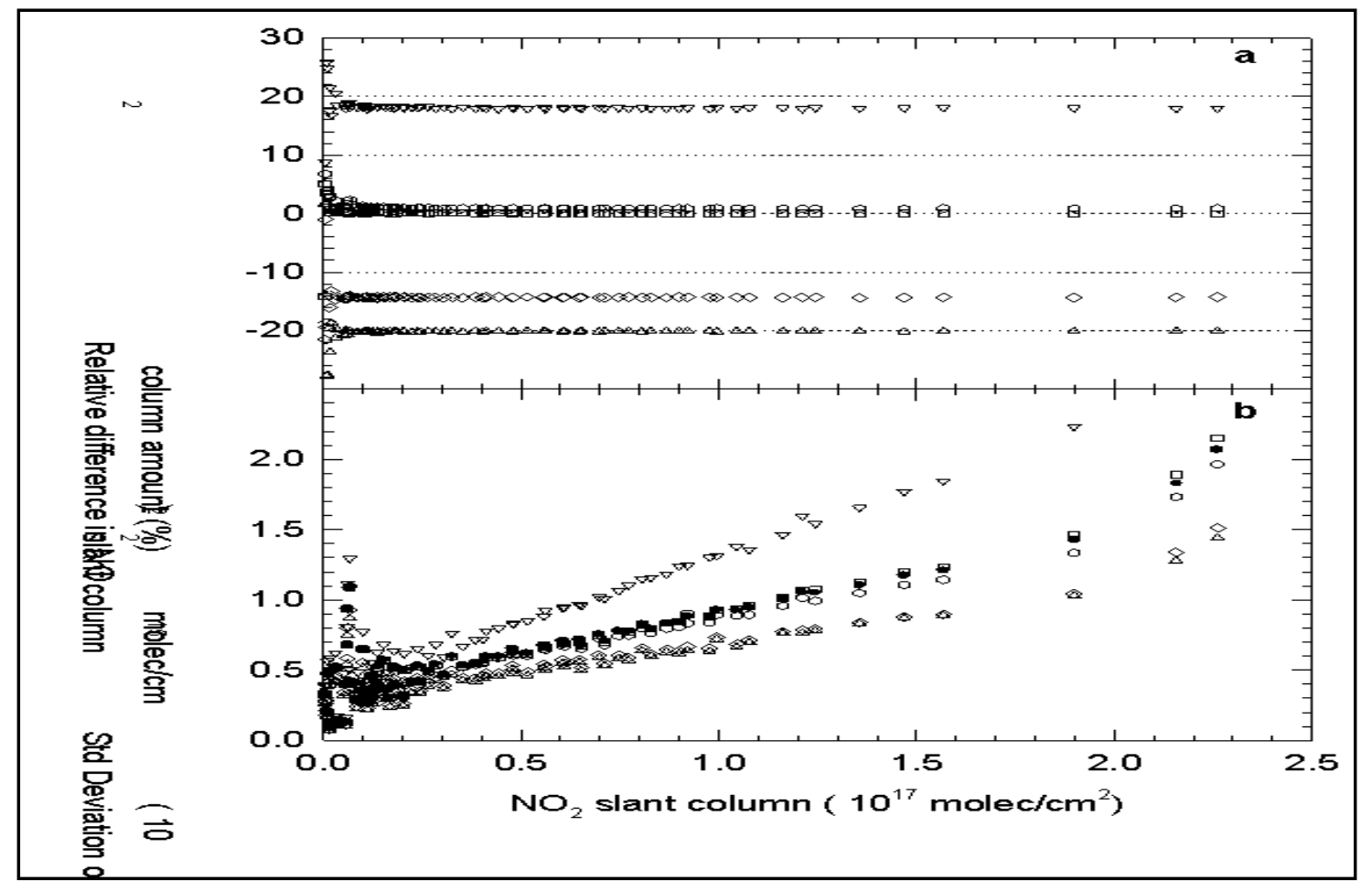

